\title{
Correlation between bone metastasis and thrombocytosis in pulmonary adenocarcinoma patients
}

\author{
WEI ZHANG ${ }^{1 *}, \mathrm{CHAO} \mathrm{YU}^{2 *}$, BIN HUANG $^{2}$, FENG-LIANG ZHOU ${ }^{2}$, HAI-DONG HUANG ${ }^{1}$ and QIANG LI ${ }^{1}$ \\ ${ }^{1}$ Department of Respiratory Medicine, Changhai Hospital, Second Military Medical University, Shanghai 200433; \\ ${ }^{2}$ Department of Respiratory Medicine, No. 413 Hospital of People's Liberation Army, Zhoushan, Zhejiang 316000, P.R. China
}

Received March 1, 2014; Accepted September 30, 2014

DOI: $10.3892 / 01.2014 .2770$

\begin{abstract}
Thrombocytosis is commonly observed in patients exhibiting a variety of malignancies, including pulmonary, gastrointestinal and hepatic cancer. In the present study, the correlation between distant metastasis and thrombocytosis was retrospectively reviewed in 308 cases of histopathologically confirmed pulmonary adenocarcinoma. The patients were classified as having thrombocytosis or not, based on their platelet counts upon diagnosis; thrombocytosis was documented in $82 / 308$ patients $(26.6 \%)$. A log-rank test indicated a statistically significant difference in survival between patients exhibiting thrombocytosis compared with patients not exhibiting thrombocytosis $(\mathrm{P}<0.001)$. In addition, the occurrence of distant metastasis and the survival period were correlated with the presence of thrombocytosis upon diagnosis. In descending order of frequency, metastases were documented at the following sites: Lymph nodes (218/308 patients; $70.8 \%$ ), bone (138/308 patients; $44.8 \%)$, lung (93/308 patients; $30.2 \%)$, brain (67/308 patients; $21.8 \%)$, liver (46/308 patients; $4.9 \%$ ), adrenal glands (11/308 patients; $3.6 \%)$ and kidneys (5/308 patients; $1.6 \%)$. Bone metastasis occurred significantly more frequently in patients exhibiting thrombocytosis $(50 / 82$ patients: $61.0 \%$; $\mathrm{P}<0.05)$ compared with patients not exhibiting thrombocytosis (88/226 patients; $38.9 \%$ ). Furthermore, according to univariate analysis, thrombocytosis, weight loss, an Eastern Cooperative Oncology Group performance status score of $\geq 2$ points, anemia, increased erythrocyte sedimentation rate, and increased alkaline phosphatase (AKP) and carcinoembryonic protein (CEA) levels were risk factors for bone metastasis. According to multivariate analysis, thrombocytosis, weight loss, and increased AKP and
\end{abstract}

Correspondence to: Dr Qiang Li, Department of Respiratory Medicine, Changhai Hospital, Second Military Medical University, 168 Changhai Road, Shanghai 200433, P.R. China

E-mail: liqi1222@yeah.net

*Contributed equally

Key words: pulmonary adenocarcinoma, platelet count, bone metastasis
CEA levels were correlated with bone metastasis. Therefore, patients exhibiting pulmonary adenocarcinoma and thrombocytosis have a higher risk of bone metastasis compared with patients not exhibiting thrombocytosis.

\section{Introduction}

Thrombocytosis is commonly observed in patients exhibiting malignant tumors. Retrospective studies have demonstrated that $10-60 \%$ of patients with untreated malignancies, such as pulmonary, gastrointestinal and hepatic cancers (1-3), exhibit increased platelet (PLT) counts. The frequency of associated thrombocytosis in primary lung cancer patients is $\sim 16-32 \%$ and PLT counts range from $350 \times 10^{9} / 1$ to $1,000 \times 10^{9} / 1$, or $>1,000 \times 10^{9} / 1$ in rare cases (4-6). Previous investigations have proposed that thrombocytosis is an independent predictor of poor prognosis in patients exhibiting malignancies, including primary lung cancer $(7,8)$.

The mechanism(s) underlying the association between thrombocytosis and malignancy remains unknown. As demonstrated in previous studies, increased concentrations of humoral factors, such as thrombopoietin, interleukin-6 and interleukin-11, stimulate PLT production in patients exhibiting malignancies (9-11). In addition, the bone marrow microenvironment (12), PLT granule protein (13) and coagulation system activation may be important in the development of reactive thrombocytosis (14).

The mechanism(s) responsible for the poor prognosis of patients exhibiting malignant tumors and concomitant thrombocytosis requires elucidation. As demonstrated by a previous study, PLT aggregation induced by tumor cells contributes to the adhesion and encapsulation of PLTs with circulating tumor cells (15). This enhances the ability of tumor cells to escape the destructive effects of immune surveillance cells, such as natural killer cells. Furthermore, tumor cell-induced PLT aggregation may promote microcirculatory adhesion and colonization of tumor cells; thus, PLTs are involved in the development of hematogenous metastases (16). In addition, activated PLTs release vascular endothelial growth factor, epidermal growth factor, PLT-derived growth factor and a number other cytokines, which stimulate the growth of malignant cells and promote angiogenesis (17). PLTs are also involved in the development of Trousseau syndrome (18); however, it is not known whether there is a statistically 
significant difference in PLT activation and its effects on prognosis between patients with and without thrombocytosis, and whether any such differences are clinically relevant. Previous clinical studies have provided no consistent evidence to support a correlation between the incidence of thrombocytosis, and tumor node metastasis (TNM) stage, differentiation or tumor size. Furthermore, according to the majority of studies $(1,3)$, the incidence of thrombocytosis is independent of the tumor pathology. Thus, the mechanism(s) responsible for the poor prognosis of patients exhibiting malignancies and concomitant thrombocytosis requires further investigation.

In the present study, the clinical data of 308 pulmonary adenocarcinoma patients were retrospectively analyzed and correlations between thrombocytosis and clinicopathological features, prognosis and distant metastases (particularly to the bone) were investigated.

\section{Patients and methods}

Patients. The records of 758 patients with histopathologically confirmed pulmonary adenocarcinoma, admitted to Changhai Hospital (Shanghai, China) from 1 July 2006 to 30 April 2009, were assessed in the present study. Patients exhibiting other tumors (previous and current), and blood, rheumatic, acute and chronic infectious or chronic inflammatory diseases, were excluded. Thus, 523 patients were selected for follow-up by telephone to obtain information regarding survival periods and distant metastasis. The median survival period was 93.9 weeks (range, 3.6-299.0 weeks) for 308/523 patients; the remaining 215 patients were lost to follow-up as they could not be contacted. The following data was collected from the study patients: i) General data, including gender, age and smoking index; and b) post-diagnostic data, including Eastern Cooperative Oncology Group performance status (ECOG PS) score (19), TNM stage (TNM, 6th edition) (20), white blood cell (WBC) count, hemoglobin, albumin, carcinoembryonic antigen (CEA) and alkaline phosphatase (AKP) levels, PLT count, erythrocyte sedimentation rate (ESR), activated partial thromboplastin time, tumor differentiation and metastasis. The overall survival (OS) was defined as the time in weeks from definite diagnosis to all-cause mortality or the termination of follow-up (30 June, 2012). Written informed consent was obtained from all patients.

Measurements and PLT counts. The date of definite diagnosis was defined as the date the Department of Pathology, Changhai Hospital received samples of the tumor. Survival was defined as the time (in weeks) from the date of definite diagnosis to all-cause mortality or the cut-off date of 30 June, 2012. Peripheral blood PLT counts were measured using an ADVIA ${ }^{\circledR} 120$ (Siemens AG, Erlangen, Germany) hematology analyzer.

Statistical analysis. Data were analyzed using SPSS software (version 17.0; SPSS Inc., Chicago, IL, USA). The normality of the PLT count distribution was determined by performing a Kolmogorov-Smirnov test and the association between thrombocytosis and tumor pathology was analyzed using univariate and multivariate analyses. The Wald test was also performed. The Cox proportional-hazards regression model, the last observation carried forward and the
Kaplan-Meier method were employed for survival analysis. In addition, inter-group comparisons of survival were based on the log-rank test and inter-group comparisons of remote metastasis were performed using the $\chi^{2}$ test. $\mathrm{P}<0.05$ was considered to indicate a statistically significant difference.

\section{Results}

General data. The present study included 308 pulmonary adenocarcinoma patients, aged $27-83$ years (mean age \pm standard deviation, 59.6 \pm 10.3 ). The gender ratio was 2.2:1 (213 male patients; 95 female patients) and TNM stage varied as follows: Stage I, 71 cases; Stage II, 32 cases; Stage IIIa, 44 cases; Stage IIIb, 49 cases; and Stage IV, 112 cases. Upon diagnosis, the mean PLT count was $246.8 \pm 91.9 \times 10^{9} / 1$; this included four (1.3\%), $222(72.1 \%)$ and 82 (26.6\%) patients with PLT counts below, within and above the normal range (100-300x10 $/ 1)$, respectively. A right-skewed distribution of PLT counts was observed (Fig. 1).

Clinicopathological characteristics. The study patients were classified as having thrombocytosis (PLT $\geq 300 \times 10^{9} / 1$; 82 cases) or not (PLT $<300 \times 10^{9} / 1 ; 226$ cases). This factor, together with various other clinicopathological factors, was subjected to univariate analysis, which revealed that an ECOG PS score of $\geq 2$ points, advanced TNM stage and leukocytosis were risk factors for thrombocytosis (Table I). According to multivariate analysis, leukocytosis, anemia and increased ESR were correlated with thrombocytosis (Table II).

Overall survival and survival rate. By final follow-up, 244/308 study patients had died and 64 study patients had survived. The one- and three-year survival rates were 76.0 and $31.5 \%$, respectively. The 82 thrombocytosis patients had a mean survival time (MST) of 60.7 weeks (range, 3.6-235.9); however, the 226 non-thrombocytosis patients had an MST of 111.6 weeks (range, 16.6-299.0). Inter-group differences between one- and three-year survival rates $(\mathrm{P}<0.001$; Table III) and within overall survival (log rank, $\chi^{2}=43.095$; $\mathrm{P}<0.001$; Fig. 2) were statistically significant.

Bone metastasis and thrombocytosis. Bone metastases were identified upon diagnosis in 29 (35.4\%) and 51 (22.6\%) patients with and without thrombocytosis, respectively. This inter-group difference was statistically significant $\left(\chi^{2}=5.127\right.$; $\mathrm{P}=0.024)$. Of the thrombocytosis patients, $50(61.0 \%)$ developed bone metastases during the course of disease progression, in comparison with 88 (38.9\%) non-thrombocytosis patients. This difference was also statistically significant $\left(\chi^{2}=11.816 ; \mathrm{P}=0.001\right)$. However, differences in metastasis to sites other than bone were not statistically significant between thrombocytosis and non-thrombocytosis patients (Table IV). According to univariate analysis, thrombocytosis, weight loss, an ECOG PS score of $\geq 2$ points, anemia, increased ESR, and increased AKP and CEA levels were risk factors for bone metastasis (Table V). According to multivariate analysis, thrombocytosis, weight loss, and increased AKP and CEA levels were correlated with bone metastasis (Table VI). 
Table I. Univariate analysis of relevant clinicopathological risk factors for thrombocytosis.

Frequency, n (\%)

Clinicopathological

factor

Thrombocytosis No thrombocytosis

OR

$95 \% \mathrm{CI}$

$\chi^{2}$ value

P-value

\section{ECOG PS score}

$\leq 1 \quad 72(87.8)$

$10(12.2)$

$217(96.0)$

$\geq 2$

$9(4.0)$

3.213

$1.262-8.180$

7.011

0.008

TMN stage
IA-IIIA
IIIA-IV
Hematological factors

29 (35.4)

$118(52.2)$

53 (64.6)

108 (47.8)

1.231

1.012-2.094

6.845

0.009

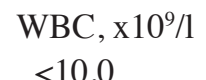

$\geq 10.0$

$61(74.4)$

21 (25.6)
$217(96.0)$
9 (4.0)

7.406

3.351-16.367

32.012

$<0.001$

$\mathrm{Hgb}, \mathrm{g} / \mathrm{l}$

$$
<120
$$

$26(31.7)$

$\geq 120$

$56(68.3)$

42 (18.6)

$184(81.4)$

0.420

0.246-0.719

6.023

0.014

Albumin, g/l

$<30$

48 (58.5)

$177(78.3)$

$\geq 30$

34 (41.5)

49 (21.7)

2.393

$1.427-4.013$

11.961

0.001

$\mathrm{ESR}, \mathrm{mm} / \mathrm{H}(\mathrm{n}=242)$

$<20$
$\geq 20$

$18(29.5)$

88 (48.6)

$43(70.5)$

$93(51.4)$

2.741

$1.609-4.670$

10.835

0.001

APTT, sec $(\mathrm{n}=258)$

$\begin{array}{lc}23-43 & 64(91.4) \\ >43 & 6(8.6)\end{array}$

AKP, U/1

$<92$

53 (64.6)

$184(97.9)$

4 (2.1)

4.985

$1.424-17.450$

5.894

0.015

$\geq 92$

29 (35.4)

$174(77.0)$

$52(23.0)$

1.896

1.129-3.184

4.740

0.029

OR, odds ratio; CI, confidence interval; ECOG PS, Eastern Cooperative Oncology Group performance status; TMN, tumor node metastasis; WBC, white blood cell; Hgb, hemoglobin; ESR, erythrocyte sedimentation rate; APPT, activated partial thromboplastin time; AKP, alkaline phosphatase.

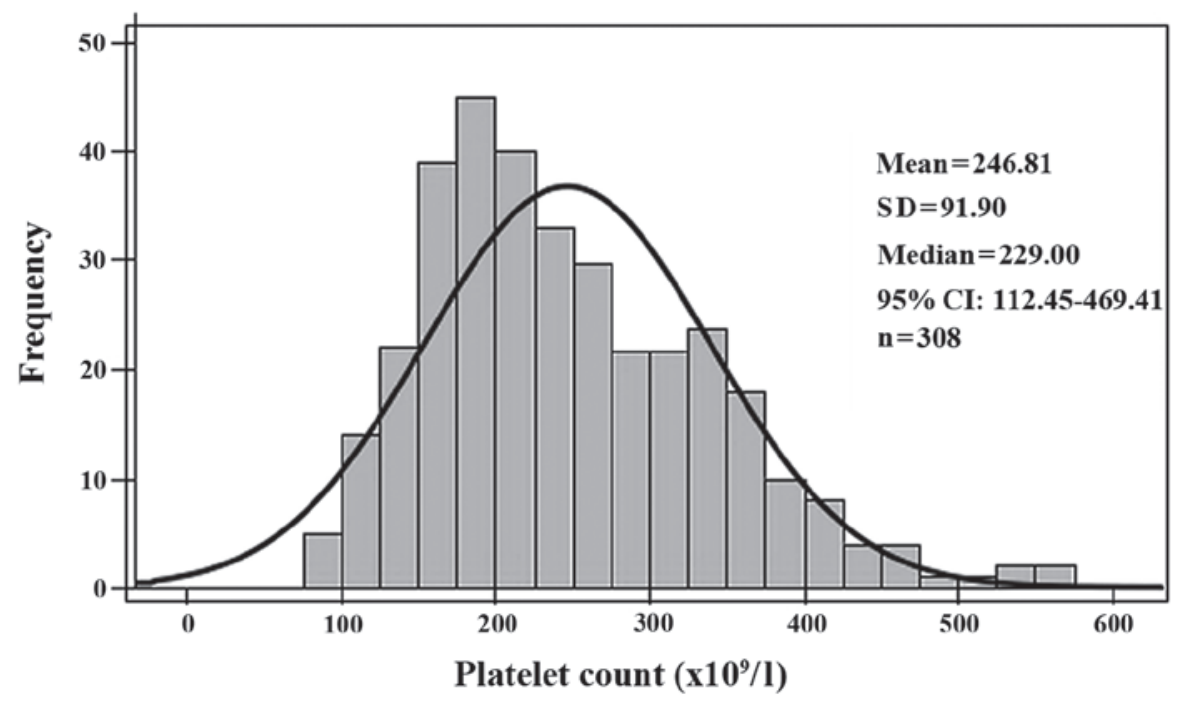

Figure 1. Peripheral blood platelet counts of 308 pulmonary adenocarcinoma patients are right-skewed (Kolmogorov-Smirnov test, Z=1.599; two-sided P-value, 0.012). SD, standard deviation; CI, confidence interval. 
Table II. Multivariate analysis of relevant clinicopathological risk factors for thrombocytosis $(\mathrm{n}=228)$.

\begin{tabular}{|c|c|c|c|c|}
\hline Risk factor & OR & $95 \%$ confidence interval & Wald value & P-value \\
\hline \multicolumn{5}{|l|}{ Fever } \\
\hline \multicolumn{5}{|l|}{ No } \\
\hline Yes & 2.575 & $1.098-6.039$ & 4.365 & 0.030 \\
\hline \multicolumn{5}{|l|}{$\mathrm{WBC}, \times 10^{9} / 1$} \\
\hline \multicolumn{5}{|l|}{$<10.0$} \\
\hline$\geq 10.0$ & 7.596 & $2.997-19.255$ & 9.941 & 0.002 \\
\hline \multicolumn{5}{|l|}{$\geq 120$} \\
\hline$<120$ & 3.360 & $1.376-4.735$ & 6.417 & 0.011 \\
\hline \multicolumn{5}{|c|}{ Albumin, g/l } \\
\hline \multicolumn{5}{|l|}{$<30$} \\
\hline$\geq 30$ & 2.543 & $1.262-5.124$ & 5.662 & 0.017 \\
\hline \multicolumn{5}{|l|}{$\mathrm{ESR}, \mathrm{mm} / \mathrm{H}$} \\
\hline \multicolumn{5}{|l|}{$<20$} \\
\hline$\geq 20$ & 2.323 & $1.194-4.517$ & 6.215 & 0.013 \\
\hline \multicolumn{5}{|l|}{ APTT, sec } \\
\hline \multicolumn{5}{|l|}{$\leq 43$} \\
\hline$>43$ & 7.869 & $1.917-32.301$ & 8.273 & 0.004 \\
\hline
\end{tabular}

OR, odds ratio; WBC, white blood cell; Hgb, hemoglobin; ESR, erythrocyte sedimentation rate; APPT, activated partial thromboplastin time.

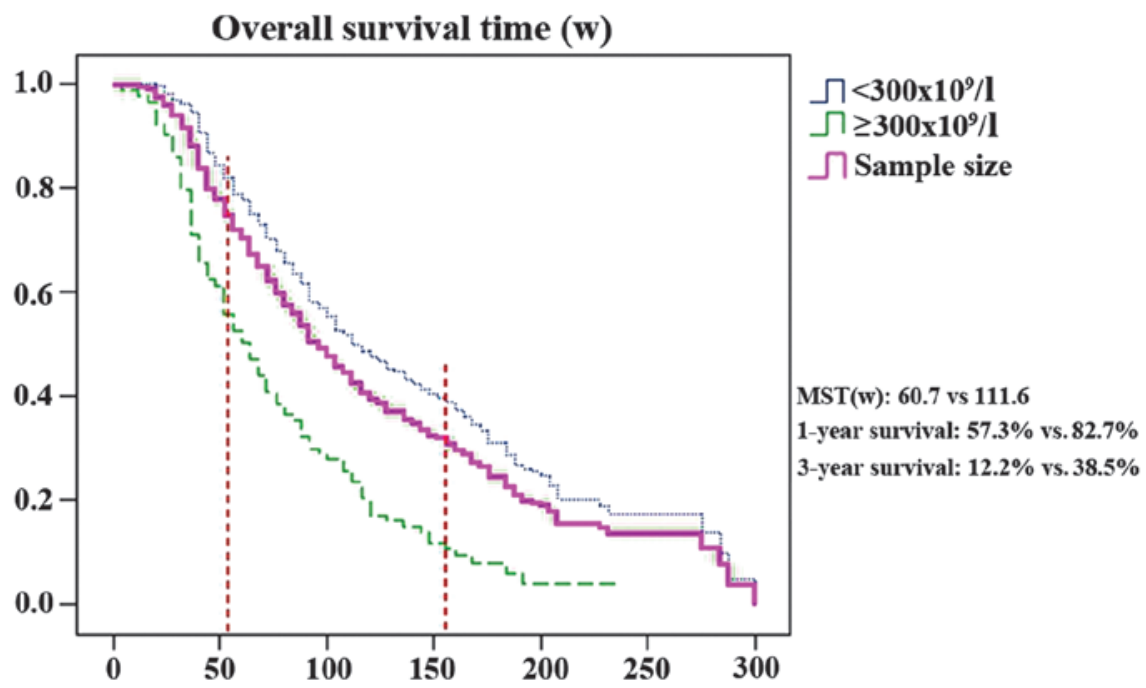

Figure 2. Survival was significantly poorer in patients exhibiting thrombocytosis compared with patients not exhibiting thrombocytosis $(\mathrm{P}<0.001)$. W, weeks; MST, mean survival time.

\section{Discussion}

Thrombocytosis can be divided into two major categories: Clonal thrombocytosis and reactive thrombocytosis. Clonal thrombocytosis is induced by clonal myeloproliferative diseases, including idiopathic thrombocythemia and polycythemia vera (11). By contrast, reactive thrombocytosis is a secondary response to various factors, including infection, cancer and tissue injury, and is the most common type of thrombocytosis. Reactive thrombocytosis has been observed in various malignancies, including lung, gastrointestinal tract and liver cancer, at a reported incidence rate of 10-60\% (1-3). In the present study, the clinical data of 308 pulmonary adenocarcinoma patients was retrospectively analyzed. The clinical characteristics of patients exhibiting thrombocytosis and pulmonary adenocarcinoma, as well as correlations between thrombocytosis and various clinicopathological factors, were investigated and are discussed from a clinical perspective.

In the current study, the incidence of thrombocytosis was $26.6 \%$, which is consistent with the $16-32 \%$ reported in studies from other countries (1-3). A PLT count of $\geq 300 \times 10^{9} / 1$ was chosen as the criterion for the diagnosis of thrombocytosis. 
Table III. Comparison of survival between thrombocytosis and non-thrombocytosis patients.

\begin{tabular}{|c|c|c|c|c|c|}
\hline Prognosis & Total, $\mathrm{n}=308$ & $\begin{array}{l}\text { Thrombocytosis, } \\
\qquad \mathrm{n}=82\end{array}$ & $\begin{array}{l}\text { No thrombocytosis, } \\
\qquad \mathrm{n}=226\end{array}$ & $\chi^{2}$ & P-value \\
\hline \multicolumn{6}{|l|}{ Outcome, n (\%) } \\
\hline Survival & $64(2.8)$ & $6(7.3)$ & $58(25.7)$ & & \\
\hline Mortality & $244(79.2)$ & $76(92.7)$ & $168(74.3)$ & 13.536 & $<0.001$ \\
\hline \multicolumn{6}{|l|}{ Prognosis } \\
\hline MST, weeks & 94.0 & 60.7 & 111.6 & & \\
\hline One-year survival, n (\%) & $234(76.0)$ & $47(57.3)$ & $187(82.7)$ & 21.310 & $<0.001$ \\
\hline Three-year survival, n (\%) & $97(31.5)$ & $10(12.2)$ & $87(38.5)$ & 19.291 & $<0.001$ \\
\hline
\end{tabular}

MST, median survival time.

Table IV. Comparison of frequency of distant metastasis between thrombocytosis and non-thrombocytosis patients.

\begin{tabular}{|c|c|c|c|c|c|}
\hline Distant metastasis site & $\begin{array}{l}\text { Sample size, } \\
\mathrm{n}(\%)(\mathrm{n}=308)\end{array}$ & $\begin{array}{l}\text { Thrombocytosis, } \\
\mathrm{n}(\%)(\mathrm{n}=82)\end{array}$ & $\begin{array}{c}\text { No thrombocytosis, } \\
\mathrm{n}(\%)(\mathrm{n}=226)\end{array}$ & $\chi^{2}$ & P-value \\
\hline \multicolumn{6}{|l|}{ Lymph node } \\
\hline Upon diagnosis & $218(70.8)$ & $61(74.4)$ & $157(69.5)$ & 0.705 & 0.401 \\
\hline During the disease course & 209 (67.9) & $59(72.0)$ & $150(66.4)$ & 0.859 & 0.354 \\
\hline \multicolumn{6}{|l|}{ Bone } \\
\hline Upon diagnosis & $80(26.0)$ & $29(35.4)$ & $51(22.6)$ & 5.127 & 0.024 \\
\hline During the disease course & $138(44.8)$ & $50(61.0)$ & $88(38.9)$ & 11.816 & 0.001 \\
\hline \multicolumn{6}{|l|}{ Lung } \\
\hline Upon diagnosis & $54(17.5)$ & $17(20.7)$ & $37(16.4)$ & 0.791 & 0.374 \\
\hline During the disease course & $93(30.2)$ & $27(32.9)$ & $66(29.2)$ & 0.396 & 0.529 \\
\hline \multicolumn{6}{|l|}{ Brain } \\
\hline Upon diagnosis & $24(7.8)$ & $7(8.5)$ & $17(7.5)$ & 0.086 & 0.769 \\
\hline During the disease course & $67(21.8)$ & $17(20.7)$ & $50(22.1)$ & 0.069 & 0.794 \\
\hline \multicolumn{6}{|l|}{ Liver } \\
\hline Upon diagnosis & $24(7.8)$ & $7(8.5)$ & $17(7.5)$ & 0.086 & 0.769 \\
\hline During the disease course & $46(14.9)$ & $13(15.9)$ & $33(14.6)$ & 0.074 & 0.785 \\
\hline \multicolumn{6}{|l|}{ Adrenal gland } \\
\hline Upon diagnosis & $6(1.9)$ & $1(1.2)$ & $5(2.2)$ & 0.311 & 0.577 \\
\hline During the disease course & $11(3.6)$ & $3(3.7)$ & $8(3.7)$ & 0.002 & 0.960 \\
\hline \multicolumn{6}{|l|}{ Kidney } \\
\hline Upon diagnosis & $2(0.6)$ & $1(1.2)$ & $1(0.4)$ & 0.563 & 0.453 \\
\hline During the disease course & $5(1.6)$ & $3(3.7)$ & $2(0.9)$ & 2.898 & 0.089 \\
\hline
\end{tabular}

Peripheral blood PLT counts exhibited a right-skewed distribution, indicating that untreated pulmonary adenocarcinoma patients have higher PLT counts than healthy subjects. Thus, the present study identified the phenomenon of pulmonary adenocarcinoma-associated thrombocytosis in Chinese patients A PLT count of $\geq 300 \times 10^{9} / 1$ was selected as the criterion for diagnosing thrombocytosis, as it defines the upper limit of the 95\% CI for PLT counts in healthy Chinese subjects. By contrast, the majority of reports from other countries use a PLT count of $\geq 400 \times 10^{9} / 1$ or $\geq 350 \times 10^{9} / 1$ as the criterion for thrombocytosis. This difference in the normal range of PLT counts between Europe and the USA, and China, must be addressed; it may be associated with differences in ethnicity and/or measurement instruments. Using pairwise comparison, Zeng et al (21) identified that the frequency of the thrombopoietin receptor (TPOR) $\mathrm{C}$ allele at position 550 is significantly higher in subjects with high PLT counts, and that thrombocytosis is associated with a $\mathrm{C}$ to A transversion at position 550 in the 5'-promoter region of TPOR (21). Therefore, the present study postulates that genetic factors may be involved in the mechanism that determines the differences in the normal range of PLT in counts in Chinese subjects versus European and American subjects.

Previous studies have found that advanced TNM stage, a high ECOG PS score and poorly differentiated carcinomas 
Table V. Univariate analysis of relevant clinicopathological risk factors for bone metastasis $(\mathrm{n}=308)$.

\begin{tabular}{|c|c|c|c|c|c|c|}
\hline \multirow[b]{2}{*}{ Risk factor } & \multicolumn{2}{|c|}{ Frequency (\%) } & \multirow[b]{2}{*}{ OR } & \multirow[b]{2}{*}{$95 \%$ CI } & \multirow[b]{2}{*}{$\chi^{2}$} & \multirow[b]{2}{*}{ P-value } \\
\hline & Bone metastasis & No bone metastasis & & & & \\
\hline \multicolumn{7}{|c|}{ Weight loss (n=288) } \\
\hline Yes & $33(41.3)$ & $39(17.1)$ & & & & \\
\hline No & $47(58.5)$ & $189(82.9)$ & 3.403 & $1.938-5.975$ & 19.274 & $<0.001$ \\
\hline \multicolumn{7}{|c|}{ ECOG PS score } \\
\hline$\geq 2$ & $11(13.8)$ & $8(3.5)$ & & & & \\
\hline$\leq 1$ & $69(86.3)$ & $220(96.5)$ & 4.384 & $1.695-11.336$ & 10.731 & 0.001 \\
\hline \multicolumn{7}{|l|}{ PLT, $x 10^{9} / 1$} \\
\hline$\geq 300$ & $29(36.3)$ & $53(23.2)$ & & & & \\
\hline$<300$ & $51(63.8)$ & $175(76.8)$ & 1.878 & $1.084-3.253$ & 8.127 & 0.008 \\
\hline \multicolumn{7}{|l|}{$\mathrm{Hgb}, \mathrm{g} / \mathrm{l}$} \\
\hline$<120$ & $25(31.3)$ & $43(18.9)$ & & & & \\
\hline$\geq 120$ & $55(68.8)$ & $185(81.1)$ & 0.511 & $0.287-0.911$ & 5.285 & 0.022 \\
\hline \multicolumn{7}{|c|}{$\mathrm{ESR}, \mathrm{mm} / \mathrm{h}(\mathrm{n}=242)$} \\
\hline$\geq 20$ & $38(68.7)$ & $98(53.9)$ & & & & \\
\hline$<20$ & $20(31.3)$ & $86(46.1)$ & 1.169 & $1.027-1.330$ & 5.320 & 0.021 \\
\hline \multicolumn{7}{|l|}{$\mathrm{AKP}, \mathrm{U} / \mathrm{l}$} \\
\hline$\geq 92$ & $39(48.8)$ & $42(18.4)$ & & & & \\
\hline$<92$ & $41(51.3)$ & $186(81.6)$ & 1.580 & $1.270-1.966$ & 28.152 & $<0.001$ \\
\hline \multicolumn{7}{|c|}{ CEA, U/l (n=287) } \\
\hline$\geq 10$ & $49(63.8)$ & $63(30.7)$ & & & & \\
\hline$<10$ & $27(36.3)$ & $148(69.3)$ & 3.969 & $2.323-6.782$ & 27.117 & $<0.001$ \\
\hline
\end{tabular}

OR, odds ratio; CI, confidence interval; ECOG PS, Eastern Cooperative Oncology Group performance status; PLT, platelet; Hgb, hemoglobin; ESR, erythrocyte sedimentation rate; AKP, alkaline phosphatase; CEA, carcinoembryonic protein.

are associated with poor prognosis in lung carcinoma (22). In the present study, univariate analysis demonstrated that an ECOG PS score of $\geq 2$ points, advanced TNM staging and leukocytosis were risk factors for decreased overall survival. Multivariate analysis demonstrated that thrombocytosis is an independent risk factor for poor prognosis in pulmonary adenocarcinoma, with a relative risk of 2.103-3.814, indicating that the mortality of pulmonary adenocarcinoma with thrombocytosis is 2.103-3.814-fold greater than non-thrombocytosis patients. Furthermore, thrombocytosis patients exhibit a significantly shorter MST compared with non-thrombocytosis patients (difference, 50.9 weeks; 60.7 vs.111.6 weeks). In addition, the one- and three-year survival rates were significantly lower compared with patients not exhibiting thrombocytosis (difference, $25.4 \%$; 57.3 vs. $82.7 \%$ and difference, $26.3 \%$, 12.2 vs. $38.5 \%$, respectively). Therefore, pulmonary adenocarcinoma patients exhibiting thrombocytosis have a worse prognosis than patients not exhibiting thrombocytosis, which is consistent with the findings reported for other malignancies.

Numerous reports from other countries support the significant effects of thrombocytosis on the survival of patients exhibiting malignancies (23-25). Thrombocytosis is a common presentation of paraneoplastic syndrome and has been recognized to accompany the development, proliferation, differentiation, invasion and metastasis of specific tumors. Furthermore, thrombocytosis may effect the survival of patients exhibiting various malignancies. Besides the stimulatory effects of activated and increased PLTs on hematogenous metastasis, tumor growth, and angiogenesis, the presence of thrombocytosis may correlate with the biological characteristics and behavior of malignant cells. Malignancies with associated thrombocytosis may possess different characteristics with regard to differentiation, invasion and metastasis compared with the same types of malignancy not associated with thrombocytosis. Furthermore, interaction of these factors may affect the patients' prognoses (26-28).

Distant metastasis is an important biological characteristic of malignant tumors and an important prognostic factor (29). In the present study, pulmonary adenocarcinoma most frequently metastasized, in descending order, to the lymph nodes, bone, lung, brain, liver, adrenal glands and kidney. Thus, the most common site of hematogenous metastases was the bone. As PLTs are produced by bone marrow, the present study assessed the correlation between PLT count and bone metastasis and identified a statistically significant correlation. The risk of bone metastasis in patients exhibiting pulmonary adenocarcinoma and thrombocytosis was 1.436-fold higher than in patients not exhibiting thrombocytosis. However, the correlation coefficient for thrombocytosis versus bone metastasis was weak. Possible explanations for the weakness of this correlation include the 
Table VI. Multivariate analysis of relevant clinicopathological risk factors for bone metastasis $(\mathrm{n}=237)$.

\begin{tabular}{lcccc}
\hline Risk factor & OR & $95 \% \mathrm{CI}$ & Wald value & P-value \\
\hline $\begin{array}{l}\text { Weight loss } \\
\quad\end{array}$ & & & & \\
$\quad$ No & & & & \\
Yes & 3.002 & $1.603-5.623$ & 11.790 & 0.001 \\
PLT, $\mathrm{x} 10^{9} / 1$ & & & & \\
$\quad<300$ & & & & \\
$\geq 300$ & 1.436 & $1.043-2.871$ & 4.013 & 0.048 \\
$\begin{array}{l}\text { AKP, U/1 } \\
<92\end{array}$ & & & & \\
$\geq 92$ & 3.466 & $1.887-6.364$ & 16.068 & $<0.001$ \\
CEA, U/1 & & & & \\
$<10$ & & & & \\
$\geq 10$ & 2.916 & $1.621-5.247$ & 12.751 & $<0.001$ \\
\hline
\end{tabular}

OR, odds ratio; CI, confidence interval; PLT, platelet; AKP, alkaline phosphatase; CEA, carcinoembryonic protein.

following: i) Reactive thrombocytosis may have been induced by a number of other factors, such as infection, rheumatic autoimmune disease and coronary heart disease $(30,31)$; b) relevant data may not have been recorded during follow-up; c) thrombocytosis may only correlate with one type of bone metastasis (osteoblastic, osteolytic or mixed) (32); and d) the small sample size may have effected the sampling error and therefore the overall findings of the study.

The present report was a retrospective study, thus, perspective and randomized sampling design were not considered and substantial relevant data was unavailable due to various factors, such as incomplete records, incomprehensible data and non-uniform reporting of data. These factors may have compromised the findings of the present study. Therefore, larger studies of tumor-induced thrombocytosis should be conducted to clarify the findings of the present report.

In conclusion, the present retrospective study of 308 pulmonary adenocarcinoma patients identified that thrombocytosis correlates with the development of bone metastases.

\section{References}

1. Pedersen LM and Milman N: Prognostic significance of thrombocytosis in patients with primary lung cancer. Eur Respir J 9: 1826-1830, 1996.

2. Aoe K, Hiraki A, Ueoka H, et al: Thrombocytosis as a useful prognostic indicator in patients with lung cancer. Respiration 71: 170-173, 2004

3. Lehmann J, Retz M, Nürnberg N, et al: The superior prognostic value of humoral factors compared with molecular proliferation markers in renal cell carcinoma. Cancer 101: 1552-1562, 2004.

4. Shimada H, Oohira G, Okazumi S, et al: Thrombocytosis associated with poor prognosis in patients with esophageal carcinoma. J Am Coll Surg 198: 737-741, 2004.

5. Suzuki K, Aiura K, Kitagou M, et al: Platelets counts closely correlate with the disease-free survival interval of pancreatic cancer patients. Hepatogastroenterology 51: 847-853, 2004.

6. Brockmann MA, Giese A, Mueller K, et al: Preoperative thrombocytosis predicts poor survival in patients with glioblastoma. Neuro Oncol 9: 335-342, 2007.
7. Iwasaki A, Hamanaka W, Harnada T, et al: Significance of platelet counts in patients who underwent surgical treatment for lung metastasis. Int Surg 92: 103-109, 2007.

8. Tomita M, Shimizu T, Hara M, et al: Prognostic impact of thrombocytosis in resectable non-small cell lung cancer. Interact Cardiovasc Thorac Surg 7: 613-615, 2008.

9. Kaushansky K: Thrombopoietin: the primary regulator of platelet production. Blood 86: 419-431, 1995.

10. Kaushansky K: Thrombopoietin the primary regulator of platelet production. Trends Endocrinol Metab 8: 45-50, 1997.

11. Schafer AI: Thrombocytosis. New Engl J Med 350: 1211-1219, 2004.

12. Slayton WB, Wainman DA, Li XM, et al: Developmental differences in megakaryocyte maturation are determined by the microenvironment. Stem cells 23: 1400-1408, 2005.

13. Sungaran R, Chisholm OT, Markovic B, et al: The role of platelet alpha-granular proteins in the regulation of thrombopoietin messenger RNA expression in human bone marrow stromal cells. Blood 95: 3094-3101, 2000.

14. Canonico S, Sciaudone G, Santoriello A, et al: Blood coagulation changes in patients with post-splenectomy persistent thrombocytosis. Chir Ital 53: 537-542, 2001 (In Italian).

15. Jurasz P, Alonso-Escolano D and Radomski MW: Platelet - cancer interactions: mechanisms and pharmacology of tumour cell-induced platelet aggregation. Br J Pharmacol 143: 819-826, 2004

16. Morimoto K, Satoh-Yamaguchi K, Hamaguchi A, et al: Interaction of cancer cells with platelets mediated by Necl-5/poliovirus receptor enhances cancer cell metastasis to the lungs. Oncogene 27: 264-273, 2008.

17. Sierko E and Wojtukiewicz MZ: Platelets and angiogenesis in malignancy. Semin Thromb Hemost 30: 95-108, 2004.

18. Bick RL: Cancer-associated thrombosis. New Engl J Med 349: 109-111, 2003

19. Oken MM, Creech RH, Tormey DC, et al: Toxicity and response criteria of the Eastern Cooperative Oncology Group. Am J Clin Oncol 5: 649-655, 1982.

20. Sobin LH and Wittekind C (eds): Rules for Classification In: International Union Against Cancer (UICC). TNM Classification of Malignant Tumours. 6th edition. Wiley-Liss, New York, NY, pp 99-103, 2002.

21. Zeng SM, Murray JC, Widness JA, Strauss RG and Yankowitz J: Association of single nucleotide polymorphisms in the thrombopoietin-receptor gene, but not the thrombopoietin gene, with differences in platelet count. Am J Hematol 77: 12-21, 2004.

22. Sawabata N, Maeda H, Yokota S, et al: Postoperative serum carcinoembryonic antigen levels in patients with pathologic stage IA nonsmall cell lung carcinoma: subnormal levels as an indicator of favorable prognosis. Cancer 101: 803-809, 2004.

23. Göğüs C, Baltaci S, Filiz E, Elhan A and Bedük Y: Significance of thrombocytosis for determining prognosis in patients with localized renal cell carcinoma. Urology 63: 447-450, 2004.

24. Ikeda M, Furukawa H, Imamura H, et al: Poor prognosis associated with thrombocytosis in patients with gastric cancer. Ann Surg Oncol 9: 287-291, 2002.

25. Hwang SG, Kim KM, Cheong JH, et al: Impact of pretreatment thrombocytosis on blood-borne metastasis and prognosis of gastric cancer. Eur J Surg Oncol 38: 562-567, 2012.

26. Connor DE and Joseph JE: Cyclic thrombocytopenia associated with marked rebound thrombocytosis and fluctuating levels of endogenous thrombopoietin and reticulated platelets: A case report. Am J Hematol 87: 120-122, 2012.

27. Onal H, Adal E, Ersen A, Onal Z and Keskindemirci G: Miliaria rubra and thrombocytosis in pseudohypoaldosteronism: case report. Platelets 23: 645-647, 2012.

28. Li AJ and Karlan BY: Androgen mediation of thrombocytosis in epithelial ovarian cancer biology. Clin Cancer Res 11: 8015-8018, 2005.

29. Chen SC, Chang HK, Lin YC, et al: Prognosis of breast cancer after supraclavicular lymph node metastasis: not a distant metastasis. Ann Surg Oncol 13: 1457-1465, 2006.

30. Chen HC, Wang CY and Wang CS: Marked thrombocytosis during treatment with ceftazidime for pulmonary infection. Pharm World Sci 30: 70-72, 2008.

31. Nanavati A, Patel $\mathrm{N}$ and Burke J: Thrombocytosis and coronary occlusion. JACC Cardiovasc Interv 5: e18-e19, 2012.

32. Roodman GD: Mechanisms of bone metastasis. New Engl J Med 350: 1655-1664, 2004. 